\title{
Floating, Flowing, Flying
}

\author{
Pieter J. Zandbergen's Life as Innovator, \\ Inspirator and Instigator in Numerical \\ Fluid Dynamics
}

\author{
edited by
}

D. Dijkstra, B.J. Geurts, J.G.M. Kuerten and H.K. Kuiken

\begin{abstract}
Faculty of Mathematical Sciences, University of Twente, Enschede, The Netherlands
\end{abstract}

Reprinted from Journal of Engineering Mathematics, Vol. 34, Nos. 1-2 (1998)

Springer-Science+Business Media, B.V. 


\section{Library of Congress Cataloging-in-Publication Data}

ISBN 978-90-481-5049-6 ISBN 978-94-017-1564-5 (eBook)

DOI 10.1007/978-94-017-1564-5

Printed on acid-free paper

All Rights Reserved

(C) 1998 Springer Science+Business Media Dordrecht

Originally published by Kluwer Academic Publishers in 1998

Softcover reprint of the hardcover 1 st edition 1998

No part of the material protected by this copyright notice may be reproduced or utilized in any form or by any means, electronic or mechanical, including photocopying, recording or by any information storage and retrieval system, without written permission from the copyright owner. 


\section{TABLE OF CONTENTS}

Dedication $1-2$

C. H. Driesen, J. G. M. Kuerten and M. Streng: Low-Reynolds-number flow over partially covered cavities

P. Wesseling, A. Segal, C. G. M. Kassels and H. Bijl: Computing flows on general two-dimensional nonsmooth staggered grids

L. Van Wijngaarden: On the sound radiated by a turbulent bubbly flow

Kris Riemslagh, Jan Vierendeels and Erik Dick: Two-dimensional incompressible Navier-Stokes calculations in complex-shaped moving domains

A. I. M. Denneman, R. J. J. Jongschaap and J. Mellema: Rheological modeling with Hookean bead-spring cubes (SC, BCC and FCC)

Bernhard Müller: Low-Mach-number asymptotics of the Navier-Stokes equations

Vassilios Theofilis: On the resolution of critical flow regions in inviscid linear and nonlinear instability calculations

$111-129$

N. Riley: Unsteady fully-developed flow in a curved pipe

$131-141$

H. Schippers: Boundary-integral-equation methods for screen problems in acoustic and electromagnetic aerospace research

R. W. C. P. Verstappen and A. E. P. Veldman: Spectro-consistent discretization of Navier-Stokes: a challenge to RANS and LES

H. K. Kuiken: A free-convection boundary-layer model for the centrifugal etching of an axisymmetric cavity

I. Moise, E. Simonnet, R. Temam and M. Ziane: Numerical simulation of differential systems displaying rapidly oscillating solutions

E. Van Groesen: Wave groups in uni-directional surface-wave models

M. Markiewicz and O. Mahrenholtz: Progressive cross waves due to the horizontal oscillations of a vertical cylinder in water. Evolution equations 227-247 


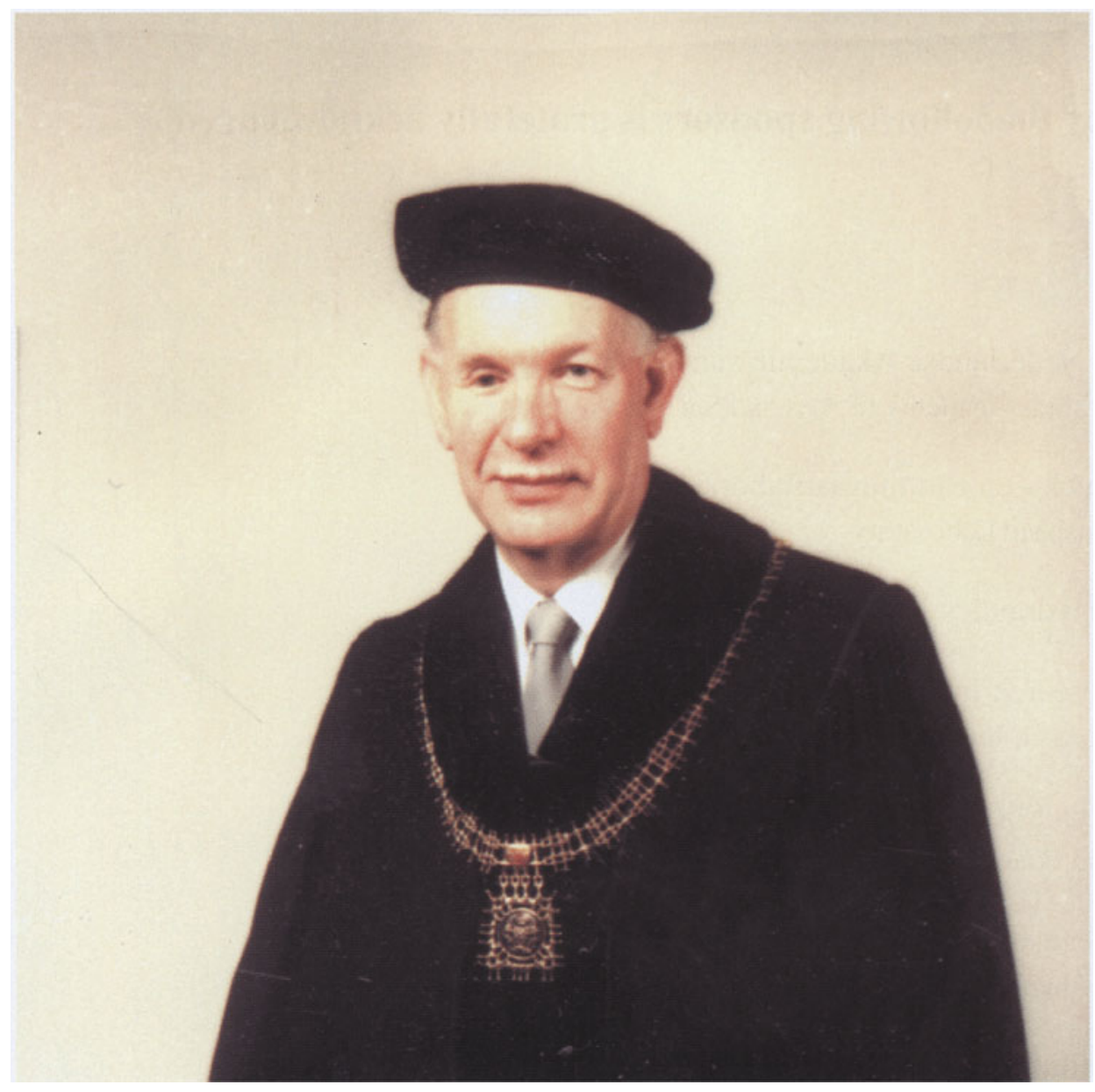

Prof.dr.ir. P.J. Zandbergen 
Support by the following sponsors is gratefully acknowledged

Koninklijke Nederlandse Akademie van Wetenschappen

Royal Netherlands Academy of Arts and Sciences

Nationaal Lucht- en Ruimtevaartlaboratorium

National Aerospace Laboratory

WL / Delft Hydraulics

Maritiem Research Instituut Nederland

Maritime Research Institute Netherlands

Universiteit en Stichting Universiteitsfonds Twente

University and Foundation University Fund Twente

Faculteit Toegepaste Wiskunde UT

Faculty of Mathematical Sciences UT

Twents Instituut voor Mechanica

Twente Institute of Mechanics 